\title{
Development of Medical Technology in Emergency Medical Services
}

\author{
V. G. Teriaev, MD, * L. L. Stazhadze, MD, L. G. Kostomorova, MD, \\ E. N. Chervochkin, MD
}

Medical science achievements, effective diagnostic, resuscitative, and intensive care techniques put into practice as well as a number of organizational measures have contributed to the advancement in the level of emergency medical care for the population. Currently, emergency medical services (EMS) systems have acquired a great deal of modern techniques and means for delivering medical care in all types of emergency conditions. But EMS has not yet developed unified forms of organization and management, and integrated approaches to the tactics of patient, and casualty treatment at the different stages of care delivery. There are neither unified personnel training programs for emergency facilities nor appropriate criteria for evaluating personnel performance in the system as a whole or any of its components. The alternative for such a situation must be the establishment of the so-called "industrial design" in EMS.

The creation of the "EMS industrial design" could allow for the application of all knowledge and experience, the establishment of comprehensive, standard approaches to treatment, and diagnostics at a national level that take into account both the abilities of a physician to make decisions and adequate service design, as well as the control of its performance. Such an approach infers that the delivery of emergency care is a unified process consisting of several stages.

Emergency medical care is provided at prehospital and inhospital stages. The main tasks in the first stage are the provision of life support within the shortest time after injury or organ and system failure both on-site and during transportation; the rapid and safe transportation to the specialized treatment facility; and adequate triage of casualties. The main task during the in-hospital stage is definitive medical treatment. The outcome is determined during the in-hospital stage through evaluation and provision of the whole complex of treatment procedures aimed at both saving the patient's life and rehabilitation for complete recovery of his or her ability to work. So the principles of EMS design must be set up on the basis of interaction between the prehospital and in-hospital stages, taking into account all the above-mentioned tasks and functions. It is a unified technological process.
The term "medical technology" is defined as a strict set of diagnostic and treatment techniques that ensure treatment quality and outcomes for certain groups of patients. Recently, many authors have pointed out the appropriateness of developing medical technologies. They see the progress in health care through scientific studies of all knowledge, experience, and skills gained in the specialty: the differentiation and definition of the task for each link in the whole technological medical care process. That means a search for an optimal system on the basis of available resources.

With performance, every involved medical person develops a certain behavioral type, the so-called "pre-scientific technology" which leads to various embarrassments, subjective assessment in the process of delivering care, and an inability to determine the effectiveness of diagnostic and treatment techniques. Only scientifically based medical technology, orientated on final outcomes can help to solve the problems.

The main difference between emergency medicine and other branches of health care lies in the responsibility of its physicians to make adequate decisions within the shortest period of time. So, the setting of medical technologies which would define the functioning regime of every EMS service link is very important. Accomplishment of such a task requires wide applications of computer techniques.

The scientific research group of the Sklifosovosky Institute for Emergency Medicine is developing an experimental computer-assisted diagnostic and treatment system (CDTS) which could be a prototype for an integrated system for all types of emergency medical conditions. The work now in progress consists of medical, medico-technological, algorithm-directed, and economic components. Medical, technological, and algorithm-directed components imply the development of optimal system design and its software, the provision of automated, computer-assisted places for work, data processing, examination, service software, and the solution of management tasks. Simultaneously, the need for all kinds of EMS resources must be defined. Only in this way can the problems of EMS organization and management as an integrated service be solved in a way that provides quality assurance of the process of rendering care in emergency conditions. The following factors com-

Sklifosovosky Scientific and Research Institute for Emergency Medicine, Moscow, USSR Reprint from Soveiskzia Meditsina 1989

*Medical Director, Emergency Medical Services, Moscow, Russia, USSR 


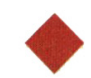

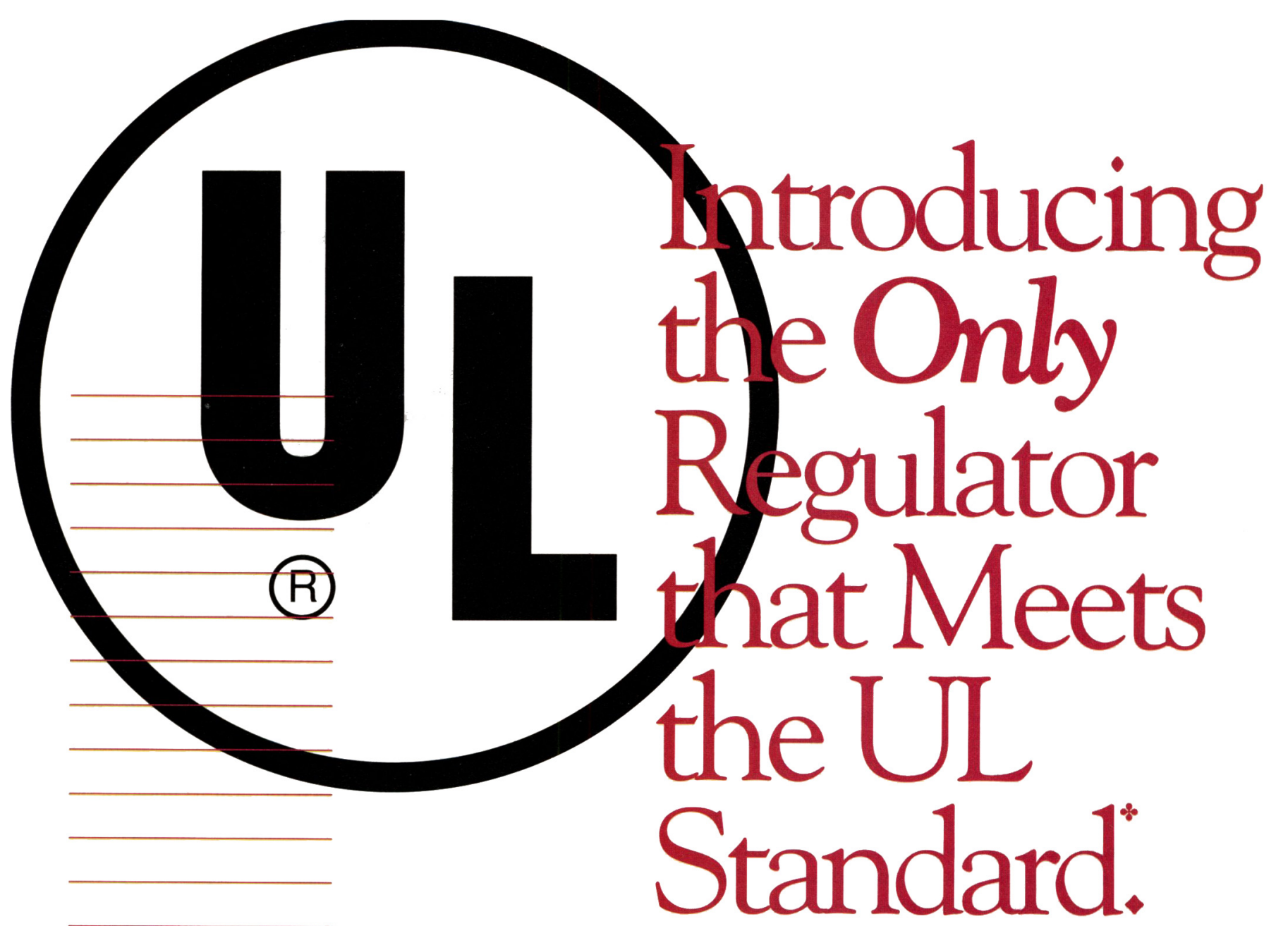

No one has met the standard of uncompromised safety... until now.

To find out what the people at Underwriters Laboratories (UL)* already know, call us today for the LSP Distributor nearest you. 1-800-225-4577

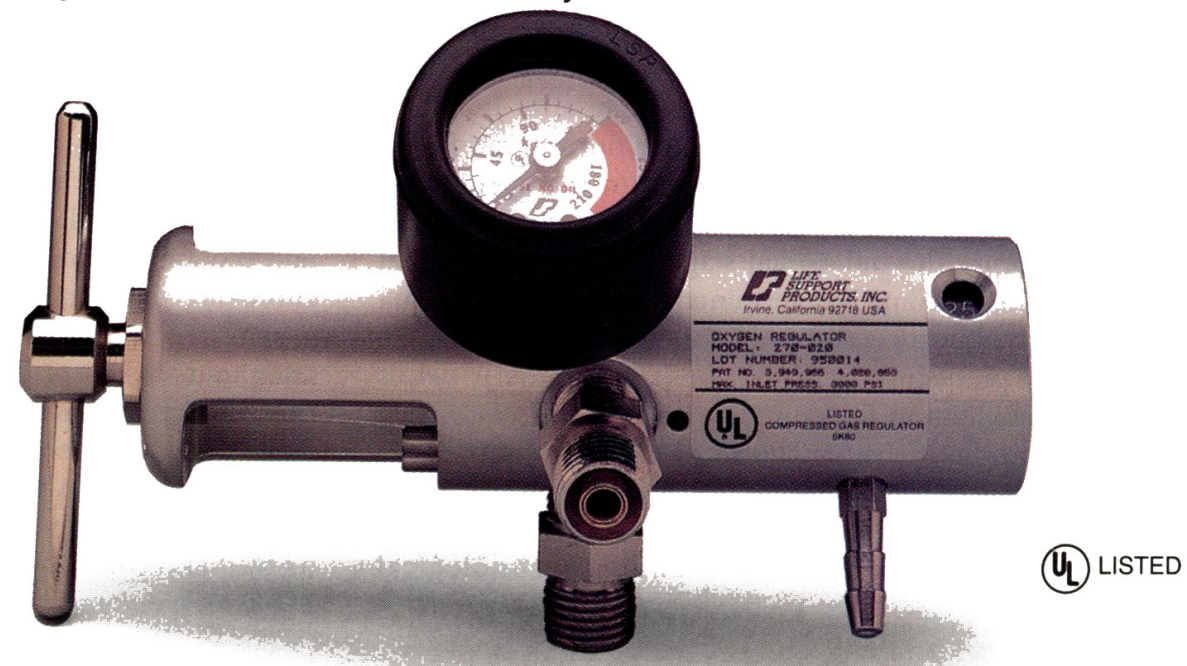

'The appearance of Underwriters Laboratories' Symbol signifies that the product meets UL's stringent manufacturing requirements. UL is an independent group recognized worldwide as a leader in conducting tests for public safety awareness.

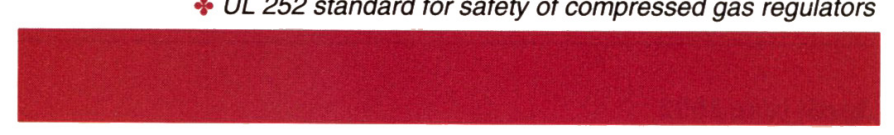


prise the basis for creating CDTS: 1) the rendering of emergency medical care without delay and with the shortest response time; 2) the evolution of vast amounts of clinical, laboratory, and instrumental investigations which are often repeated; 3) the great amount of data processing required to choose treatment tactics; 4) the creation and extension of an automated data bank on the different diagnostic and treatment modalities for emergency conditions; 5) lack of available, skilled physicians in EMS; and 6) the necessity of consultative emergency services for remote sites using radio communications.

\section{Medical components}

Medical components must include the formation of diagnostic-related-groups of patients. The next task for medical research is the development of diagnostic and treatment schemes for every stage in the delivery of emergency care, taking into account available resources in health care. It is important to establish criteria for the effectiveness of treatment for each stage in the delivery of care which will test, evaluate, and correct all developed technologies.

Thus, the medical components include: 1) categorization of clinical conditions into diagnostic-related groups; 2) determination of the treatment diagnostic processes in successive stages, and rehabilitation for every clinico-statistical group; 3) identification of an optimal volume of the medical care and determination of demands for the personnel and materialtechnical resources for each stage of the emergency medical care with due regard for clinico-statistical groups; 4) develop indicators that are sufficient for the optimal treatment of patients in each of the different clinico-statistical groups; 5) develop criteria for the evaluation of the effectiveness of treatment for each of the stages of emergency medical care; 6) creation of the clinical knowledge base required for the development of an expert system in diagnosis and treatment of emergency conditions; and 7) approbation and clinical tests for effectiveness of developed technology.

\section{Medical-technical and program-algorithmic components}

The creation of automated, computer-assisted systems make it possible to establish specific tasks for each of the above-mentioned components of scientific research. Definition of the optimal structure of the system must include: automated work- place, modeling a system for the development of automated functioning of the workplace; ALDS (Algorithm Diagnostic Systems) for determination of the optimal parameters for organization of the structural-functional system; and definition of the medico-technical demands for the medical techniques and the computerized, automated workplaces. Identification of the complexities of the system includes: 1) registration data about the patient (passport data, etc.); and 2) provision of a treatment-diagnostic expert system inclusive of the data bank, automated workplace, administrative tasks, including the statistical processing of the data, service program, etc.

\section{Organization-economic components}

The economic components of such a system should include: 1) Calculation of the optimal and maximum permissible in rendering medical aid according to the developed medical technology (in the concrete ALDS); 2) Substantiation of the standards and norms of all aspects for provision with treatment-diagnostic process; 3) Evaluation of medico-social and economical effectiveness of the developed and installed ALDS; and 4) Development of the standards for evaluation of quality for every element of the ALDS work.

Creation of the above-mentioned system will allow: 1) acceptance of the standards of treatment-diagnostic processes and hence should unify the components of the system rendering medical care to a contingent of patients, limiting it within the frames of the necessary and sufficient manipulations; 2) exposure of the vulnerable spots of the technological process; 3) creation of working management; and 4) adjustment of the true succession of the emergency medical care in different sub-divisions, being part of the whole, but having specific tasks, order of work, volumes, and succession of conducted procedures. The instruments required for evaluating the economical and medical effectiveness of any EMS subdivisions and EMS as a whole should be created. Standardization of decisions is most significant in conditions of mass hospitalization of the injured during accidents and catastrophes.

The described system is intended for perspective-for the working-out of the common principles for the creation of medical technologies in the system of EMS service will allow the introduction of new elements in the future, and will be able to correct them while receiving the scientific data. 


\section{First Announcement and Call}

\section{TH WORLD CONGRESS ON EMERgency AND DisASTER MEDICINE}

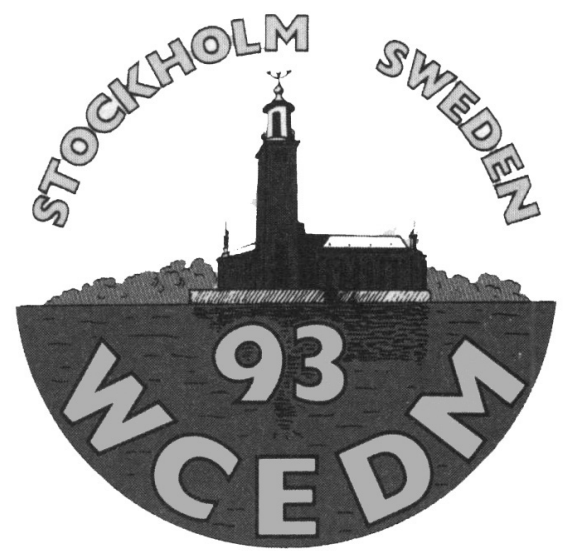

\section{0-23 JUNE 1993 - STOCKHOLM, SWEDEN}

Presented by the Swedish Society for Disaster Medicine on behalf of the World Association for Emergency and Disaster Medicine

WCEDM ' 93 will focus on disasters and emergencies related to extreme weather conditions, sea transportation, chemical and biological warfare agents, and risk assessment, particularly in connection with nuclear plants and more.
The scientific program of 8th World Congress on Emergency and Disaster Medicine will include state of the art lectures by internationally reknown authorities, symposia, workshops and free paper presentations.
Scientific Committee Gosta Artursson, Sweden Jan de Boer, Netherlands William Gunn, Switzerland Borje Hallen, Sweden Sten Lennquist, Sweden Karl-Axel Norberg, Sweden (Chairman) Lars Weisaeth, Norway David Yates, Great Britain Scientific advisory board Jacob Adler, Israel V. Ananthranam, Singapore Peter Baskett, Great Britain Leo Bossaert, Belgium
Marvin Birnbaum, USA Howard Champion, USA Herman de Looz, Belgium Wolfgang Dick, Germany James Ducharme, Canada Xavier Emmanuelli, France Judith Fisher, Great Britain Wojcieck Gaszynski, Poland Michael Gunderson, USA Bertil Hamberger, Sweden Martin Holmdahl, Sweden Mathias Kalina, Canada Knut Jessen, Denmark Sten Lindahl, Sweden Kristian Lexow, Norway Valeri Losakow, USSR Tom Lundin, Sweden
Michele Masellis, Italy Matti Mattila, Finland Marko Murtomaa, Finland Michael Moles, Hong Kong Vicente Monterosso, Brazil Bernhard Nemitz, France Richard Novak, USA Erik Noij, USA Harry Oxer, Australia Jiri Pokorny, Czechoslovakia J. Drabkova, Czechoslovakia Peter Safar, USA Emil Stoyanov, Bulgaria Lars Thoren, Sweden Takashi Ukai, Japan Yasohiro Yamamoto, Japan Bjorn Zetterstrom, Sweden

\section{CALL FOR PRESENTATIONS}

The World Association for Emergency and Disaster Medicine is calling for presentations for the WCEDM '93. Individuals interested in submitting

proposals may obtain presentation packets from:

Congress Secretariat, WCEDM '93, c/o Stockholm Convention Bureau

P.O. Box 6911, S-102 39 Stockholm, Sweden. 